\title{
Improvement of system security with unified-power- flow controller at suitable locations under network contingencies of interconnected systems
}

\author{
D. Thukaram, L. Jenkins and K. Visakha
}

\begin{abstract}
The operation and planning of large interconnected power systems are becoming increasingly complex. To maintain security of such systems, it is desirable to estimate the effect of contingencies and plan suitable measures to improve system security/stability. The paper presents an approach for selection of unified-power-flow-controller (UPFC-) suitable locations considering normal and network contingencies after evaluating the degree of severity of the contingencies. The ranking is evaluated using composite-criteria-based fuzzy logic for eliminating masking effects. The fuzzy approach, in addition to real-power loadings and bus-voltage violations, also used voltagestability indexes at the load buses as the post-contingent quantities to evaluate the networkcontingency ranking. The selection of UPFC-suitable locations uses the criteria on the basis of improved system security/stability. The proposed approach for selection of UPFC-suitable locations has been tested under simulated conditions on a few power systems and the results for a 205-node real-life equivalent regional-power-grid system of three interconnected utility systems are presented for illustration purposes.
\end{abstract}

\section{Introduction}

The history of the power industry has been one of steadily expanding integration, which means the development and use of interconnections between power systems so that their combined loads and resources can be treated as a unit system to achieve the advantage of large-scale operation. Potential benefits of cross-border interconnection of large systems are great and at the same time the costs for such interconnection are also significant. Potential benefits include financial savings, environmental protection, reliability enhancement and others. Interconnection may necessitate reinforcement of existing networks to satisfy stability or other reliability considerations. The reinforcement may be assisted by the deployment of flexible AC-transmission-system (FACTS) devices and computercontrolled energy-management systems (EMS). The planning and operation of power systems are becoming increasingly complex [1].

A number of recent incidents have illustrated that modern power systems are prone to widespread failures. In today's operating environment, conventional planning and operating methods can leave systems exposed to instabilities, which often go undetected until it is too late. Voltage instability is one of the phenomena which have led to major blackouts. Today's interconnected power systems are very complex and may include sophisticated devices such as high-speed excitation systems, HVDC, FACTS and

\section{(C) IEE, 2005}

IEE Proceedings online no. 20045235

doi:10.1049/ip-gtd:20045235

Paper received 4th November 2004

The authors are with the Department of Electrical Engineering, Indian Institute of Science, Bangalore 560 012, India

E-mail: dtram_2001@yahoo.com energy-storage systems. Satisfactory system performance depends heavily on the co-ordination of all controls and protections associated with these devices.

In power-system planning, various types of studies are carried out, considering various system-operational scenarios. Intended and unintended switching operations are considered for very-fast transient conditions and protective measures are planned for the purpose. Under dynamic conditions such as faults, line openings, generator tripping, load throw off etc., protective systems are designed with more emphasis on protecting the equipment than concern to system security and stability. However, judicious use of dynamic controls at generating systems, excitation/governor systems, HVDC systems, static VAR compensators (SVCs) and, more recently, FACTS devices will help to maintain the system security/stability.

In a day-to-day operation, it may be beyond the operator's scope to take any control decision during emergencies. However, the operator can use various control devices and also SVCs and UPFC to restore the system to normal conditions. In a planning study it may be prohibitive to carry out dynamic studies for an exhaustive set of contingencies. Thus it is important to evaluate exhaustive numbers of static contingency studies and obtain the set of important severe contingencies for detailed dynamic analysis.

Most contingency-ranking methods rank the contingencies in an approximate order of severity with respect to a scalar performance index (PI), which quantifies the system stress [2-5]. It has been pointed out that two separate ranking lists are required for real power-flow problems and voltage-profile problems, respectively, since the contingencies causing line overloads do not necessarily cause busvoltage violations and vice versa. Thus, two performance indexes, which give measures for line overloads and for bus-voltage violations, respectively, are needed for real 
power- and voltage-contingency rankings [6]. The common disadvantage of several PI-based ranking methods is the masking phenomenon.

With increased loading of existing power-transmission systems, the problem of voltage stability and voltage collapse has also become a major concern in power-system planning and operation. It has been observed that voltage magnitudes do not give a good indicator of proximity to a voltage-stability limit and voltage collapse [7, 8]. Therefore, in network contingency ranking, it is necessary to consider voltage-stability indexes at all the load buses as the postcontingent quantities, in addition to real power loadings and bus-voltage violations for estimating the actual system stress under a contingency. Suitable measures/preventive control actions can then be planned to improve system security/stability.

The most comprehensive device which has emanated from the FACTS initiative is the unified-power-flow controller (UPFC) [9, 10]. The UPFC regulates the activeand reactive-power control as well as adaptive-to-voltagemagnitude control simultaneously, or any combination of them. Controlling the power flows in the network, under normal conditions and network contingencies, help to reduce flows in heavily loaded lines, reduce system power loss, and improve the stability and performance of the system without generation rescheduling or topological changes [11]. Because of the considerable costs of the FACTS devices, it is important to ascertain the location for placement of these devices which is suitable for various network contingencies.

The locations of the UPFC device in the power system are obtained on the basis of static and/or dynamic performances. There are several methods for finding locations of UPFC in vertically integrated systems but little attention has been devoted to interconnected power systems under network contingencies. In this paper, for selection of suitable locations of UPFC, voltage-stability L index of load buses and minimum singular-value MSV have been used as the basis for improved system security/stability after evaluating the degree of severity of the considered contingency $[12,13]$. The ranking is evaluated using a composite-criteria-based fuzzy approach for eliminating masking effects. The fuzzy approach uses voltage-stability indexes at the load buses as the post-contingent quantities, in addition to real power loadings and bus-voltage violations to evaluate the network-contingency ranking. The proposed approach for selection of UPFC-suitable locations has been tested under simulated conditions on a few power systems, and the results for a 205-node real-life equivalent regional-power-grid system of three interconnected utility systems are presented for illustration purposes.

\section{Voltage-stability-index (L-index) computation}

Consider a system where $n$ is the total number of buses with $1,2, \ldots, g$ generator buses, and $g+1, \ldots, n$ remaining $(n-g)$ buses. For a given system operating condition, using the load-flow (state-estimation) results, the voltage-stability $\mathrm{L}$ index is computed as [13],

$$
\boldsymbol{L}_{j}=\left|1-\sum_{i=1}^{g} F_{j i} \frac{V_{i}}{V_{j}}\right|
$$

where $j=g+1, \ldots, n$ and all the terms within the sigma on the right-hand side of (1) are complex quantities. The values of $\boldsymbol{F}_{\boldsymbol{j} i}$ are complex and are obtained from the network $\boldsymbol{Y}$-bus matrix. For a given operating condition,

$$
\left[\begin{array}{l}
\boldsymbol{I}_{G} \\
\boldsymbol{I}_{L}
\end{array}\right]=\left[\begin{array}{cc}
\boldsymbol{Y}_{G G} & \boldsymbol{Y}_{G L} \\
\boldsymbol{Y}_{L G} & \boldsymbol{Y}_{L L}
\end{array}\right]\left[\begin{array}{l}
\boldsymbol{V}_{G} \\
\boldsymbol{V}_{L}
\end{array}\right]
$$

where $\boldsymbol{I}_{G}, \boldsymbol{I}_{L}$ and $\boldsymbol{V}_{G}, \boldsymbol{V}_{L}$ represent complex current and voltage vectors at the generator nodes and load nodes. $\left[\boldsymbol{Y}_{G G}\right],\left[\boldsymbol{Y}_{G L}\right],\left[\boldsymbol{Y}_{L L}\right]$ and $\left[\boldsymbol{Y}_{L G}\right]$ are corresponding partitioned portions of the network $\boldsymbol{Y}$-bus matrix. Rearranging (2) we obtain

$$
\left[\begin{array}{c}
\boldsymbol{V}_{L} \\
\boldsymbol{I}_{G}
\end{array}\right]=\left[\begin{array}{ll}
\boldsymbol{Z}_{L L} & \boldsymbol{F}_{L G} \\
\boldsymbol{K}_{G L} & \boldsymbol{Y}_{G G}
\end{array}\right]\left[\begin{array}{c}
\boldsymbol{I}_{L} \\
\boldsymbol{V}_{G}
\end{array}\right]
$$

where $\left[\boldsymbol{F}_{L G}\right]=-\left[\boldsymbol{Y}_{L L}\right]^{-1}\left[\boldsymbol{Y}_{\mathrm{LG}}\right]$

For stability, the index $L_{j}$ must not be violated (maximum limit $=1$ ) for any of the nodes $j$. Hence, the global indicator $L$ describing the stability of the complete subsystem is given by $L=$ maximum of $L_{j}$ for all $j$ (load buses). An $L$-index value away from 1 and close to 0 indicates improved system security. For an unloaded system with generator/load buses voltages $1.0 \angle 0$, the $L$ indices for load buses are close to zero, indicating that the system has maximum stability margin. For a given network, as the load/generation increases, the voltage magnitude and angles change near maximum-power-transfer condition and the voltage-stability index $L_{j}$ values for load buses tend to close to unity, indicating that the system is close to voltage collapse. While the different methods give a general picture of the proximity of the system voltage collapse, the $L$ index gives a scalar number to each load bus. Among the various indices for voltage-stability and voltage-collapse prediction, the $L$ index gives fairly consistent results. The $\mathrm{L}$ indices for given load conditions are computed for all the load buses and the maximum of the $L$ indices gives the proximity of the system to voltage collapse.

\section{The approach}

The following describes the major steps involved in the approach for contingency ranking and selection of suitable locations of UPFC for system-security improvement in an interconnected utility system.

(i) For the given system, exhaustive network-contingency analyses are carried out.

(ii) Contingency ranking using various criteria such as line loading, bus-voltage profiles and voltage-stability indexes of load buses are carried out.

(iii) The contingency ranking is evaluated using the composite-criteria-based fuzzy approach.

(iv) Since most of the contingencies may not threaten system security/stability, those contingencies that pose serious system security/stability are selected for each zone.

(v) A set of five/six most severe contingencies for each zone, in the order of severity, is identified which needs additional supporting devices such as UPFC to improve the system conditions.

(vi) Based on the above set of network contingencies for each zone, a few transmission lines for each zone are considered for placement of UPFC devices.

(vii) Analyses are carried out with placement of UPFC in three or four selected transmission lines for the contingency cases in each zone.

(viii) Based on the improved performance, the most suitable location and the next most suitable for UPFC is obtained for each zone. 


\section{Fuzzy approach for contingency ranking}

The proposed fuzzy approach uses voltage-stability indexes at the load buses as the post-contingent quantities, in addition to real power loadings and bus-voltage violations to evaluate the network contingency ranking. The line loading, bus-voltage profile and voltage-stability indexes are divided into different categories and are expressed in fuzzyset notation. The severity indexes are also divided into different categories. The fuzzy rules are used evaluate the severity of each post-contingent quantity.

\subsection{Line loading}

The post-contingent percentage line loadings are divided into four categories using fuzzy-set notations: lightly loaded (LL), $0-50 \%$; normally loaded (NL), $50-85 \%$; fully loaded (FL), 85-100\%; over-loaded (OL), above $100 \%$. Figure 1 shows the correspondence between line loading and the four linguistic variables.

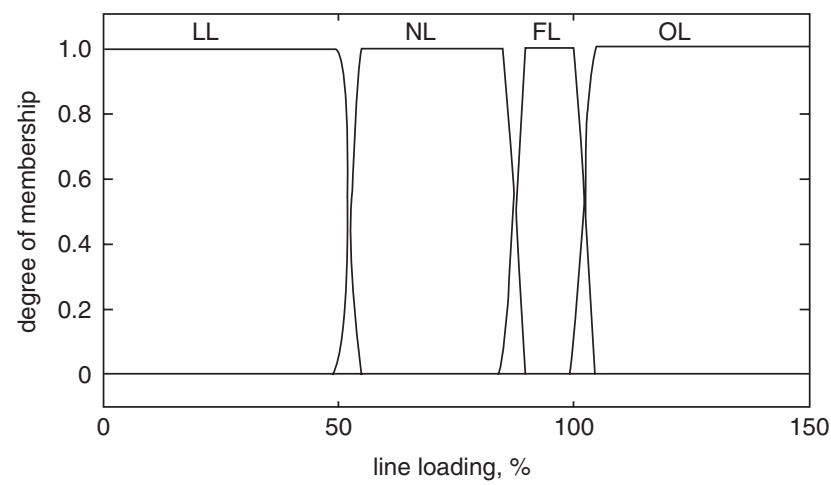

Fig. 1 Line loading and the corresponding linguistic variables

\subsection{Bus-voltage profiles}

The post-contingent bus-voltage profiles are divided into three categories using fuzzy-set notations: low voltage (LV), below 0.9 p.u; normal voltage (NV), 0.9-1.02 p.u; and over voltage $(\mathrm{OV})$, above 1.02 p.u. Figure 2 shows the correspondence between bus-voltage profiles and the three linguistic variables.

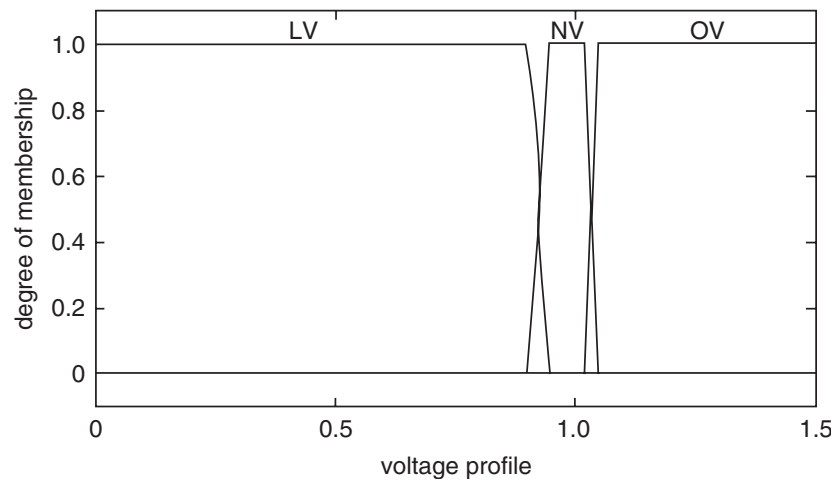

Fig. 2 Voltage profiles and the corresponding linguistic variables

\subsection{Voltage-stability indexes}

The post-contingent voltage-stability indexes are divided into five categories using fuzzy-set notations: very low index (VLI), 0-0.2; low index (LI), 0.2-0.4; medium index (MI), $0.4-0.6$, high index $(\mathrm{HI}), 0.6-0.8$; and very high index (VHI), above 0.8. Figure 3 shows the correspondence between bus-voltage-stability indexes and the five linguistic variables.

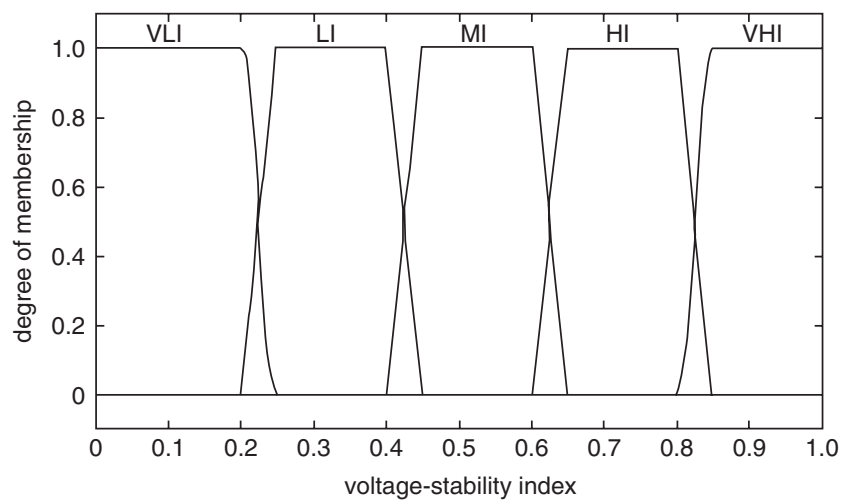

Fig. 3 Voltage-stability index and the corresponding linguistic variables

The fuzzy rules, which are used for evaluation of severity indexes of post-contingent quantities of the line loading, bus-voltage profiles and voltage-stability indexes are given in Table 1.

\section{Table 1: Fuzzy rules}

\begin{tabular}{|c|c|c|c|c|}
\hline Post-contingent quantity & Severity & & & \\
\hline $\begin{array}{llll}\mathrm{LL} & \mathrm{NL} & \mathrm{FL} & \mathrm{OL}\end{array}$ & LS BS & AS & MS & \\
\hline LV NV OV & MS BS & MS & & \\
\hline $\begin{array}{lllll}\text { VLI } & \mathrm{LI} & \mathrm{MI} & \mathrm{HI} & \mathrm{VHI}\end{array}$ & VLS LS & BS & AS & MS \\
\hline
\end{tabular}

$\mathrm{VLS}=$ very less severe; $\mathrm{LS}=$ less severe $\mathrm{BS}=$ below severe; $\mathrm{AS}=$ above severe $\mathrm{MS}=$ more severe

After obtaining the severity indexes (SI) of all the line loadings, bus-voltage profiles and voltage-stability indexes the overall-severity indexes (OSI) for a particular line outage are obtained using the expressions

$$
\left.\begin{array}{l}
O S I_{L L}=\sum w_{L L} S I_{L L} \\
O S I_{V P}=\sum w_{V P} S I_{V P} \\
O S I_{\text {ISI }}=\sum w_{\text {ISI }} S I_{\text {ISI }}
\end{array}\right\}
$$

where $w_{L L}, w_{V P}, w_{V S I}=$ weighting coefficients for severity indexes of line loading, voltage profile and voltage-stability indexes, respectively.

$S I_{L L}, S I_{V P}, S I_{V S I}=$ severity indexes of post-contingent line loading, voltage profile and voltage stability indexes, respectively.

The effect of these weighting coefficients is that the overall severity index is first dominated by the severity index MS, and next by the severity indexes AS, BS, LS, and VLS, respectively. Thus the overall severity index reflects the actual severity of the system for a contingency.

\subsection{Computation of network composite overall-severity index (NCOSI)}

The network composite overall-severity index (NCOSI) is obtained by adding all the three overall severity indexes as shown in Fig. 4. When the overall severity index for each contingency in the contingency list is obtained, the overall severity indexes for those contingency cases with a severity index exceeding a prespecified value are listed, and ranked according to the network composite overall-severity index.

\section{Selection of UPFC-suitable locations}

It is proposed to improve the performance of the system by selecting suitable locations for UPFC in each zone using all 


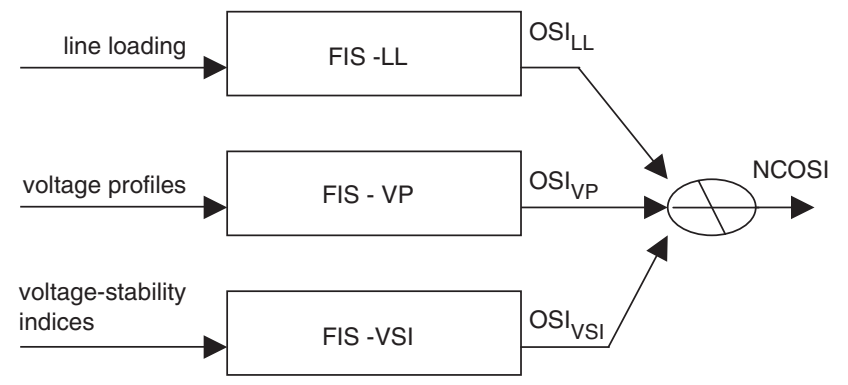

Fig. 4 Parallel-operated fuzzy-inference systems (FIS)

of its advantages under network contingencies. Studies are carried out with UPFC in three locations for two contingency cases in each zone. A contingency may involve a line having UPFC, and thus two locations for UPFC are selected based on the best performance of the system. These two locations of UPFCs can take care of severe network contingencies for the system studied.

\subsection{UPFC equivalent circuit}

The UPFC equivalent circuit for a steady-state model as shown in Fig. 5 has been used in the evaluation of system performance under network contingency.

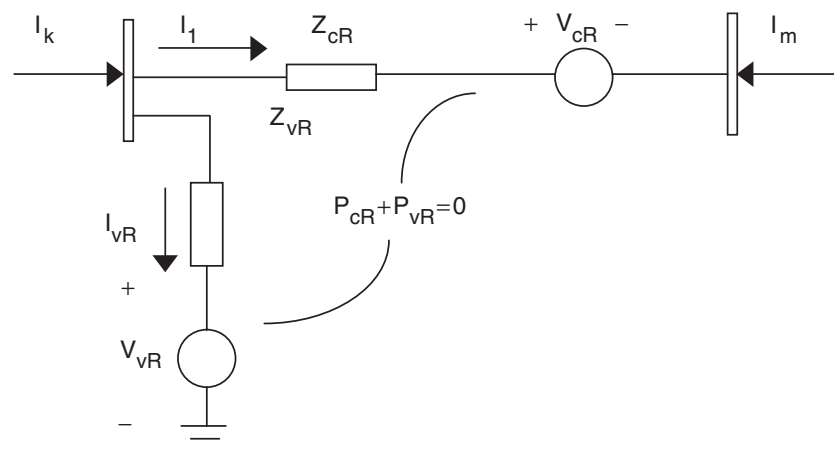

Fig. 5 UPFC equivalent circuit

The equivalent circuit consists of two ideal voltage sources,

$$
\left.\begin{array}{l}
V_{c R}=V_{c R}\left(\cos \theta_{c R}+\sin \theta_{c R}\right) \\
V_{v R}=V_{v R}\left(\cos \theta_{v R}+\sin \theta_{v R}\right)
\end{array}\right\}
$$

where $V_{v R}$ and $\theta_{v R}$ are the controllable magnitude $\left(V_{v R \min } \leq V_{v R} \leq V_{v R \max }\right)$ and angle $\left(0 \leq \theta_{v R} \leq 2 \pi\right)$ of the parallel-voltage source. The magnitude $V_{c R}$ and angle $\theta_{c R}$ of the series voltage source are controlled between limits $\left(V_{c R \min } \leq V_{c R} \leq V_{c R \max }\right)$ and angle $\left(0 \leq \theta_{c R} \leq 2 \pi\right)$, respectively [14].

\subsection{Computational procedure}

The following are the major computational steps involved in the approach for selection of UPFC location under a given network contingency.

Step 1: Identify the transmission corridors for the given network.

Step 2: Select a few transmission lines as suitable locations for each transmission corridor.

Step 3: Perform the power-flow/voltage-stability analysis with UPFC connected in the selected line for each transmission corridor for a given network contingency.
Step 4: Compute the performance of the voltage stability improvement indexes $\mathscr{L}_{\mathrm{L}}$ of the load buses and minimum singular value (MSV):

$$
\mathscr{L}_{\mathrm{L}}=\sum_{j=g+1}^{n}\left(L_{j}^{\text {old }}-L_{j}^{\text {new }}\right)
$$

where $L_{j}^{\text {old }}, L_{j}^{\text {new }}=$ initial and new voltage-stability index of a load bus j under a contingency

Step 5: Prepare a list indicating location of UPFC, the value of $\mathscr{L}_{\mathrm{L}}$, maximum value of voltage stability index $L_{\max }$ and minimum singular value (MSV).

Step 6: From the above list, one can identify the most suitable location for UPFC, which gives a maximum value for $\mathscr{L}_{\mathrm{L}}$.

\section{Real life 205-bus equivalent-system studies}

\subsection{Contingency ranking}

The fuzzy approach for contingency ranking is applied on a real-life system of a 205-bus equivalent regional-power-grid system of three interconnected utility systems (three zones), as shown in Fig. 6. The system has 20 generator buses and 185 other $400 \mathrm{kV}$ and $220 \mathrm{kV}$ buses. The system has 22 tapregulating transformers, 25 fixed-tap transformers, and 236 transmission lines. The system total peak load is about $7982 \mathrm{MW}, 4564 \mathrm{MVAR}$. There are shunt reactors connected at various $400 \mathrm{kV}$ buses for transient-overvoltage protection. The ranking of all the $400 \mathrm{kV}$-line outage contingencies, using the approach proposed in Section 4, is given in Table 2 .

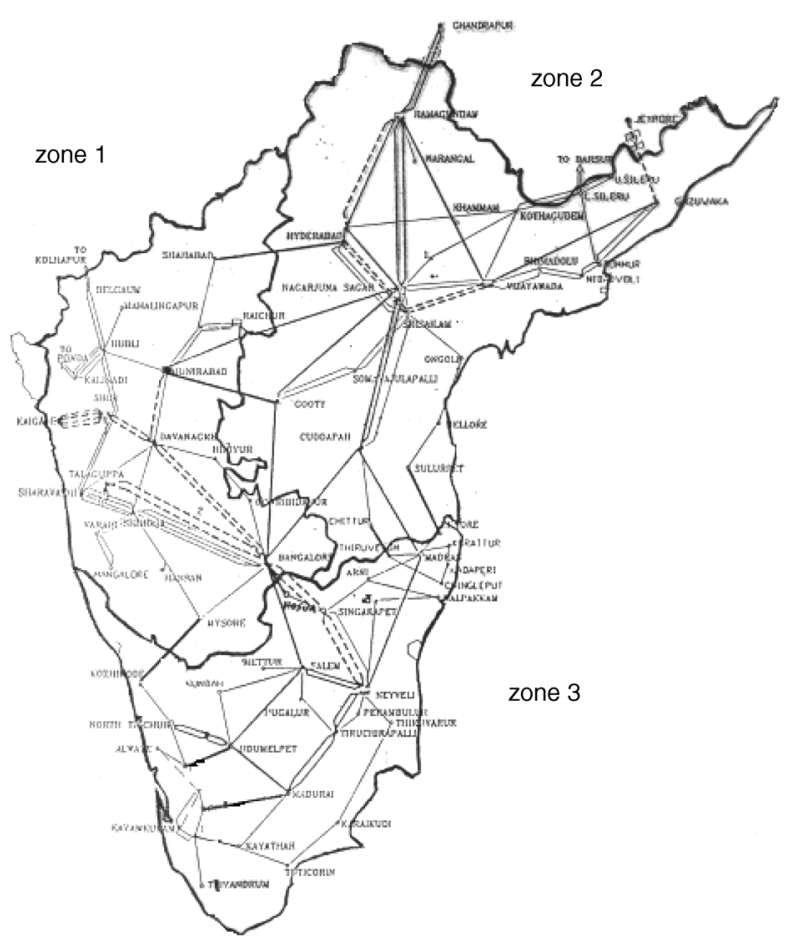

Fig. 6 Zonal grid map of interconnected system

6.2 Most severe contingencies in each zone Since most of the contingencies may not threaten system security/stability, those contingencies that pose serious system security/stability are selected. A set of five most severe contingencies in each zone, in the order of severity, is identified which needs additional supporting devices. Based 
Table 2: Overall severity indexes and ranks

\begin{tabular}{|c|c|c|c|c|c|}
\hline $\begin{array}{l}\text { Line connected } \\
\text { between buses }\end{array}$ & $\mathrm{OSI}_{L L}$ & $\mathrm{OSI}_{V P}$ & $\mathrm{OSI}_{V S I}$ & NCOSI & Rank \\
\hline \multicolumn{6}{|l|}{ Zone: 1} \\
\hline 156 and 162 & 1640.1 & 4534.3 & 2239.1 & 8413.5 & 5 \\
\hline 156 and 127 & 1728.8 & 4560.2 & 2223.5 & 8512.5 & 2 \\
\hline 156 and 170 & 1568.9 & 3915.5 & 2246.4 & 7730.8 & 13 \\
\hline 117 and 157 & 1767.4 & 4075.1 & 2224.7 & 8067.2 & 8 \\
\hline 117 and 158 & 1731.8 & 5186.4 & 2434.9 & 9353.1 & 1 \\
\hline 157 and 118 & 1635.6 & 4622.4 & 2230.6 & 8488.6 & 3 \\
\hline 157 and 60 & 1630.6 & 4443.0 & 2233.5 & 8307.1 & 6 \\
\hline 118 and 60 & 1625.0 & 3891.8 & 2177.8 & 7694.6 & 14 \\
\hline 158 and 187 & 1548.2 & 3772.1 & 2141.6 & 7461.9 & 18 \\
\hline \multicolumn{6}{|l|}{ Zone: 2} \\
\hline 187 and 127 & 1656.2 & 4124.1 & 2206.9 & 7987.2 & 9 \\
\hline 162 and 139 & 1610.3 & 3850.8 & 2150.0 & 7611.1 & 15 \\
\hline 163 and 82 & 1612.1 & 4016.7 & 2170.4 & 7799.2 & 11 \\
\hline 128 and 163 & 1531.2 & 3435.4 & 2125.7 & 7092.3 & 27 \\
\hline 164 and 83 & 1583.2 & 3641.8 & 2158.7 & 7383.7 & 19 \\
\hline 23 and 128 & 1592.8 & 3552.2 & 2127.4 & 7272.4 & 23 \\
\hline 23 and 161 & 1566.9 & 3643.9 & 2162.8 & 7373.6 & 20 \\
\hline 187 and 161 & 1555.2 & 3529.0 & 2130.5 & 7214.7 & 24 \\
\hline 23 and 187 & 1564.5 & 3645.3 & 2139.7 & 7349.5 & 21 \\
\hline 187 and 162 & 1639.3 & 4077.5 & 2174.8 & 7891.6 & 10 \\
\hline 161 and 164 & 1554.6 & 3437.9 & 2126.6 & 7119.1 & 26 \\
\hline 164 and 163 & 1538.6 & 3529.7 & 2127.7 & 7196.0 & 25 \\
\hline \multicolumn{6}{|l|}{ Zone: 3} \\
\hline 170 and 140 & 1874.7 & 4164.4 & 2122.6 & 8161.7 & 7 \\
\hline 142 and 140 & 1798.4 & 4368.5 & 2278.6 & 8445.5 & 4 \\
\hline 181 and 139 & 1535.5 & 3626.0 & 2125.1 & 7286.6 & 22 \\
\hline 181 and 141 & 1538.2 & 3857.8 & 2152.7 & 7548.7 & 16 \\
\hline 141 and 142 & 1550.5 & 3803.3 & 2135.1 & 7488.9 & 17 \\
\hline 181 and 170 & 1632.9 & 4010.4 & 2153.8 & 7797.1 & 12 \\
\hline
\end{tabular}

Table 3: Five most severe contingencies in the zone 1 and ranks

\begin{tabular}{lll}
\hline $\begin{array}{l}\text { Line connected } \\
\text { between buses }\end{array}$ & Bus names & Rank \\
\hline 117 and 158 & GDHLI4-RTPS4 & 1 \\
156 and 127 & SOMH4-GOOTY4 & 2 \\
157 and 118 & DVG4-HOD4 & 3 \\
156 and 162 & SOMH4-CUDP4 & 5 \\
157 and 60 & DVG4-NLM4 & 6 \\
\hline
\end{tabular}

on the above set of network contingencies, a few transmission lines are considered for placement of UPFC devices. The set of five most severe contingencies in each region is given in Tables 3-5.

\subsection{UPFC location}

Performance of the system has been evaluated with UPFC in three locations under two severe-contingency cases in each zone. Based on the improved performance of the system, the best and next-best locations for UPFC placement are obtained. The improved performance of the
Table 4: Five most severe contingencies in the zone 2 and ranks

\begin{tabular}{llc}
\hline $\begin{array}{l}\text { Line connected } \\
\text { between buses }\end{array}$ & Bus names & Rank \\
\hline 187 and 127 & NGSGR4-GOOTY4 & 9 \\
187 and 162 & NGSGR4-CUDPH4 & 10 \\
163 and 82 & VJWAD4-VISKP4 & 11 \\
162 and 139 & CUDP4-SPBUDUR4 & 15 \\
164 and 83 & SRSLM4-APCBDS4 & 19 \\
\hline
\end{tabular}

Table 5: Five most severe contingencies in the zone 3 and ranks

\begin{tabular}{llc}
\hline $\begin{array}{l}\text { Line connected } \\
\text { between buses }\end{array}$ & Bus names & Rank \\
\hline 142 and 140 & MADURAI4-UDMLPT4 & 4 \\
170 and 140 & SALEM4-UDMLPT4 & 7 \\
181 and 170 & N2MINE-4-SALEM4 & 12 \\
181 and 141 & N2MINE4-TIRUCHY4 & 16 \\
141 and 142 & TIRUCHY4-MADURAI4 & 17 \\
\hline
\end{tabular}


system is determined based on the improvement in voltage stability $\mathrm{L}$ indices and minimum singular value.

\subsection{UPFC location in zone 1}

6.4. 1 Rank-1 contingency (line outage 117158): In this contingency, for a peak-load condition, the overall total real power loss is $240.36 \mathrm{MW}(2.92 \%)$. The minimum voltage is 0.8141 p.u. at bus 28 and the maximum voltage-stability index $L_{\max }$ is 0.7760 at bus 21 . The selected transmission lines for possible UPFC placements under rank-1 contingency are the lines connected between buses 156 and 127, 157 and 118 and 162 and 156. The summary of results of UPFC placement under rank-1 contingency is given in Table 6.

Table 6: Summary of results of UPFC placement under rank-1 contingency

\begin{tabular}{|c|c|c|c|c|}
\hline \multirow[t]{2}{*}{ Parameter } & \multirow[t]{2}{*}{ Initial } & \multicolumn{3}{|c|}{$\begin{array}{l}\text { UPFC location in line connected between } \\
\text { buses }\end{array}$} \\
\hline & & 156 and 127 & 157 and 118 & 162 and 156 \\
\hline $\mathscr{L}_{\mathrm{L}}$ & - & 1.1933 & 2.4377 & 1.0057 \\
\hline$L_{\max }$ & 0.7760 & 0.7612 & 0.7605 & 0.7630 \\
\hline$V_{\min }$ & 0.8141 & 0.8242 & 0.8441 & 0.8218 \\
\hline $\begin{array}{l}\text { Power } \\
\text { loss (MW) }\end{array}$ & 240.36 & 236.27 & 234.82 & 235.85 \\
\hline MSV & 0.1000 & 0.0795 & 0.1020 & 0.0882 \\
\hline
\end{tabular}

From Table 6, it can be observed that the UPFC location in line 157-118 has a high value for $\mathscr{L}_{\mathrm{L}}$, which indicates that the improvement in voltage-stability indexes is more compared with that for the UPFC location in other lines. Also, the value of $V_{\min }$ and power loss are less for the UPFC location in line 157-118. It is also observed that the minimum singular value (MSV) is higher as given in the above Table 6 . Therefore the most suitable line for UPFC placement under the rank-1 contingency is line 157-118. The initial and final (best location) bus voltages and voltage stability indices of the selected $400 \mathrm{kV}$ buses in both cases are shown in Figs. 7 and 8, respectively.

\subsubsection{Rank-2 contingency (line outage 156-}

127): In this contingency, for a peak-load condition, the overall total real power loss is $227.10 \mathrm{MW}(2.77 \%)$. The minimum voltage is 0.8241 p.u. at bus 31 and the maximum voltage-stability index $L_{\max }$ is 0.7850 at bus 21 . The selected transmission lines for possible UPFC placements under rank-2 contingency are the lines connected between buses 156 and 127, 157 and 118 and 162 and 156. The summary of results of UPFC placement under rank-2 contingency is given in Table 7.

Note from the above Table 7 that the UPFC location in line $157-118$ has a high value for $\mathscr{L}_{\mathrm{L}}$, which indicates that the improvement in voltage stability indices is more compared with those in the UPFC location in other lines. Also the values of $L_{\max }$ and power loss are less for the UPFC location in line 157-118. It is also observed that the minimum singular value (MSV) is higher, as shown in Table 7. Therefore the most suitable line for UPFC placement is $157-118$ under the rank-2 contingency. The initial and final (best-location) bus voltages and voltage-

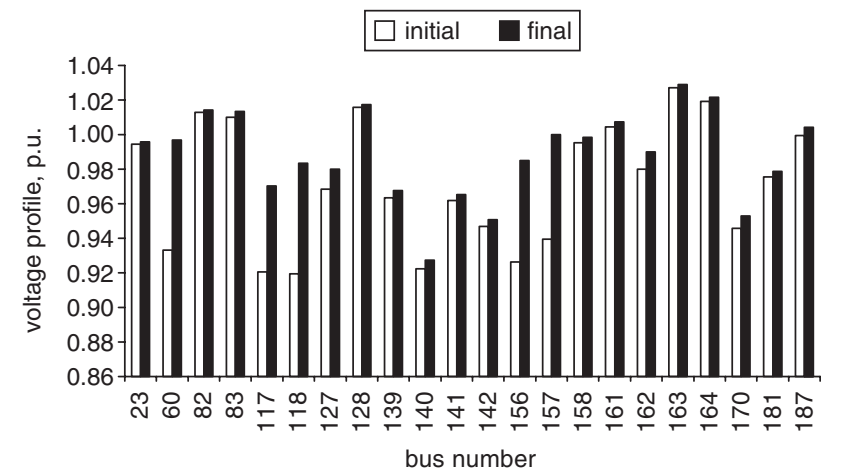

Fig. 7 Voltage profiles

Rank-1 contingency

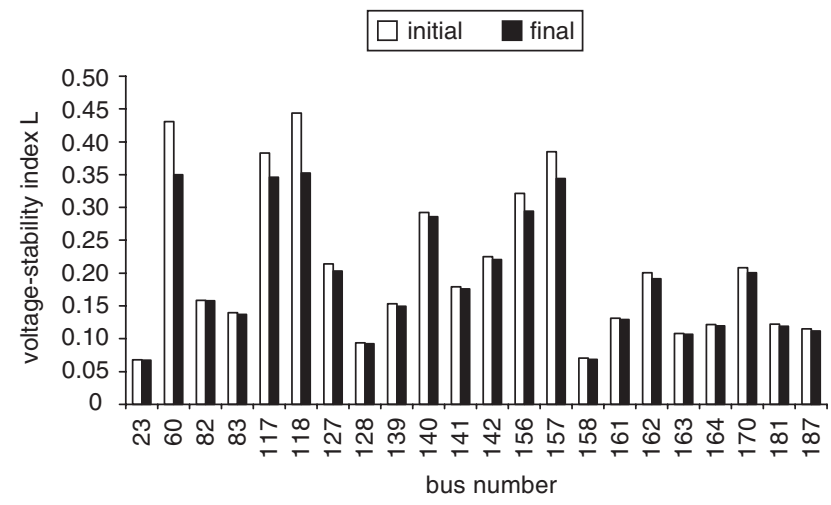

Fig. 8 Voltage-stability indexes

Rank-1 contingency

Table 7: Summary of results of UPFC placement under rank-2 contingency

\begin{tabular}{|c|c|c|c|c|}
\hline \multirow[t]{2}{*}{ Parameter } & \multirow[t]{2}{*}{ Initial } & \multicolumn{3}{|c|}{$\begin{array}{l}\text { UPFC location in line connected between } \\
\text { buses }\end{array}$} \\
\hline & & 156 and 117 & 157 and 118 & 162 and 156 \\
\hline $\mathscr{L}_{\mathrm{L}}$ & - & 0.5557 & 1.8687 & 0.8147 \\
\hline$L_{\max }$ & 0.7850 & 0.7809 & 0.7720 & 0.7736 \\
\hline$V_{\min }$ & 0.8241 & 0.8318 & 0.8602 & 0.8322 \\
\hline $\begin{array}{l}\text { Power } \\
\text { loss (MW) }\end{array}$ & 227.10 & 223.74 & 221.12 & 224.08 \\
\hline MSV & 0.0976 & 0.0786 & 0.0986 & 0.0786 \\
\hline
\end{tabular}

stability indexes of the selected $400 \mathrm{kV}$ buses in both cases are shown in Figs. 9 and 10, respectively.

\subsection{UPFC location in zone 2}

6.5.1 Rank-9 contingency (line outage 187127): In this contingency, for a peak-load condition, the overall total real power loss is $224.88 \mathrm{MW}(2.74 \%)$. The minimum voltage is 0.8388 p.u. at bus 31 and the maximum voltage-stability index $L_{\max }$ is 0.775 at bus 21 . The selected transmission lines for possible UPFC placements under rank-9 contingency are the lines connected between buses 187 and 162, 162 and 139 and 164 and 83. The summary of results of UPFC placement under rank-9 contingency is given in Table 8.

From Table 8, it can be seen that the UPFC location in line $187-162$ has a high value for $\mathscr{L}_{\mathrm{L}}$, which indicates that the improvement in voltage-stability indexes is greater than 


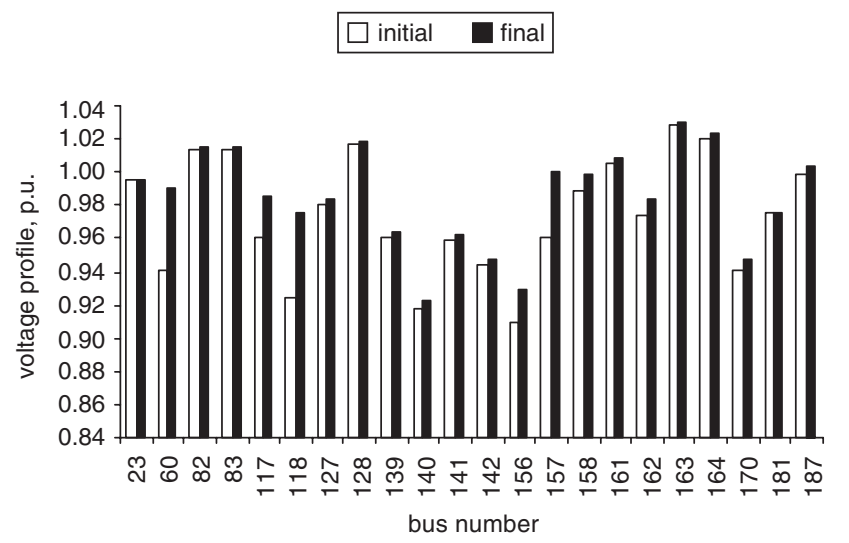

Fig. 9 Voltage profiles

Rank-2 contingency

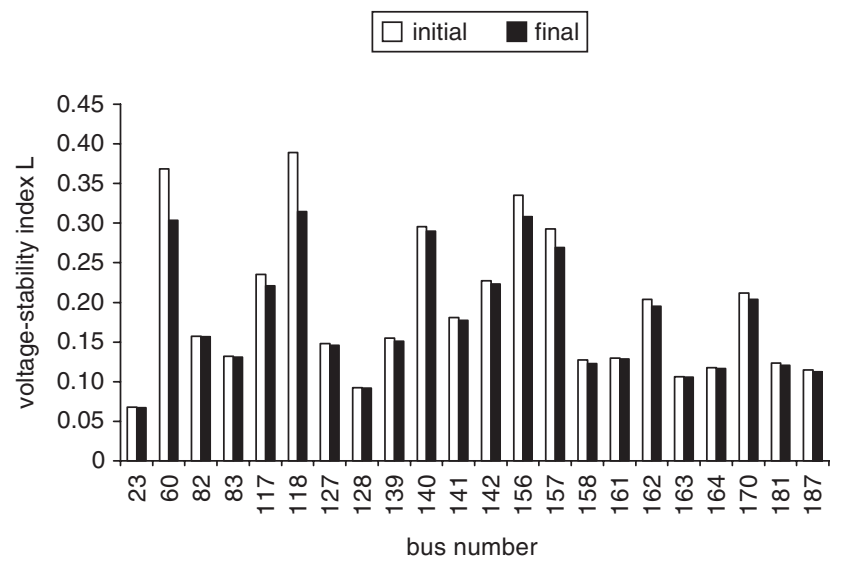

Fig. 10 Voltage-stability indexes

Rank-2 contingency

Table 8: Summary of results of UPFC placement under rank-9 contingency

\begin{tabular}{lcccc}
\hline Parameter & Initial & \multicolumn{4}{l}{$\begin{array}{l}\text { UPFC location in line connected between } \\
\text { buses } \\
\text { 187 and } 162\end{array}$} & 162 and 139 & 164 and 83 \\
\hline $\mathscr{L}_{\mathrm{L}}$ & - & 2.6369 & 0.1693 & 0.0151 \\
$L_{\max }$ & 0.7750 & 0.7435 & 0.7590 & 0.7745 \\
$V_{\min }$ & 0.8388 & 0.8581 & 0.8499 & 0.8393 \\
Power & 224.88 & 222.05 & 225.96 & 224.74 \\
loss (MW) & & & & \\
MSV & 0.1070 & 0.1090 & 0.1065 & 0.1021 \\
\hline
\end{tabular}

the UPFC location in other lines. Also the values of $L_{\max }$ and power loss are less for the UPFC location in line 187162. It is also observed that the minimum singular value (MSV) is higher, as given in Table 8. Therefore the most suitable line for UPFC placement under the rank-9 contingency is $187-162$. The initial and final (best-location) bus-voltage-stability indexes of the selected $400 \mathrm{kV}$ buses in both cases are shown in Fig. 11.

\subsubsection{Rank-10 contingency (line outage 187-}

162): In this contingency, for a peak-load condition, the overall total real power loss is $222.88 \mathrm{MW}(2.72 \%)$. The minimum voltage is $0.8425 \mathrm{p}$.u. at bus 31 and the maximum voltage-stability index $L_{\max }$ is 0.7730 at bus 21 . The selected transmission lines for possible UPFC placements under

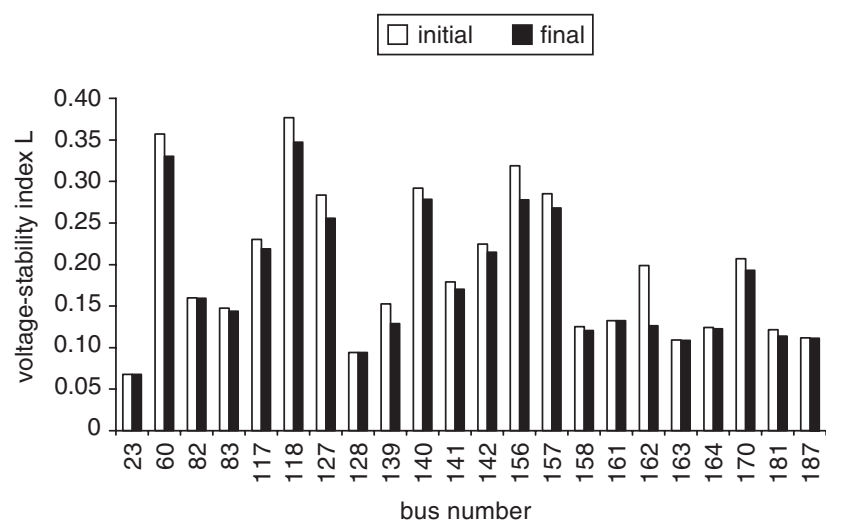

Fig. 11 Voltage-stability indexes

Rank-9 contingency

Table 9: Summary of results of UPFC placement under rank-10 contingency

\begin{tabular}{|c|c|c|c|c|}
\hline \multirow[t]{2}{*}{ Parameter } & \multirow[t]{2}{*}{ Initial } & \multicolumn{3}{|c|}{$\begin{array}{l}\text { UPFC location in line connected between } \\
\text { buses }\end{array}$} \\
\hline & & 187 and 127 & 162 and 139 & 164 and 83 \\
\hline $\mathscr{L}_{\mathrm{L}}$ & - & 1.5071 & 0.1541 & -0.0009 \\
\hline$L_{\max }$ & 0.7730 & 0.7532 & 0.7556 & 0.7726 \\
\hline$V_{\min }$ & 0.8425 & 0.8554 & 0.8538 & 0.8428 \\
\hline $\begin{array}{l}\text { Power } \\
\text { loss (MW) }\end{array}$ & 222.88 & 219.97 & 224.73 & 224.15 \\
\hline MSV & 0.1021 & 0.1092 & 0.1064 & 0.0974 \\
\hline
\end{tabular}

rank-10 contingency are the lines connected between buses 187 and 127, 162 and 139 and 164 and 83. The summary of results of UPFC placement under rank-10 contingency is given in Table 9.

From Table 9, it can be observed that the UPFC location in line 187-127 has a high value for $\mathscr{L}_{\mathrm{L}}$, which indicates that the improvement in voltage-stability indexes is greater than for the UPFC location in other lines. Also the values of $L_{\max }$ and power loss are less for the UPFC-location line 187-127. Note that the MSV is higher, shown Table 9. It can also be seen that the value of $\mathscr{L}_{\mathrm{L}}$ is negative, which indicates that there is no improvement of the systemvoltage-stability indexes and that the power loss has increased from the initial value $222.88 \mathrm{MW}$ to around $224 \mathrm{MW}$ for the UPFC location in lines $162-139$ and 164 83. Therefore the most suitable line for UPFC placement under the rank-10 contingency is the line 187-127. The initial and final (best-location) bus-voltage-stability indexes of the selected $400 \mathrm{kV}$ buses in both cases are shown in Fig. 12.

\subsection{UPFC location in zone 3}

6.6.1 Rank-4 contingency (line outage 142140): In this contingency, for a peak-load condition, the overall total real power loss is $235.91 \mathrm{MW}(2.87 \%)$. The minimum voltage is 0.8207 p.u. at bus 21 and the maximum voltage-stability index $L_{\max }$ is 0.9750 at bus 21 . The selected transmission corridors for possible UPFC placements under rank-4 contingency are the lines connected between buses 141 and 142, 181 and 141 and 181 and 70. The summary of results of UPFC placement under rank-4 contingency is given in Table 10. 


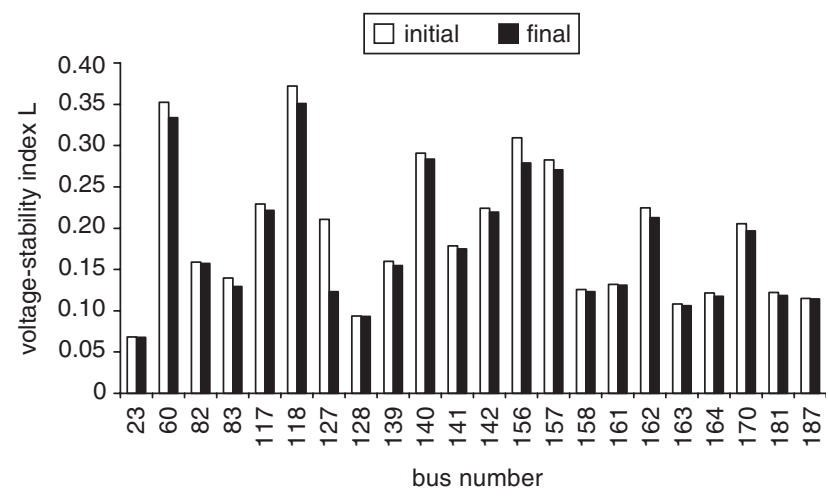

Fig. 12 Voltage-stability indexes

Rank-10 contingency

Table 10: Summary of results of UPFC placement under rank-4 contingency

\begin{tabular}{|c|c|c|c|c|}
\hline \multirow[t]{2}{*}{ Parameter } & \multirow[t]{2}{*}{ Initial } & \multicolumn{3}{|c|}{$\begin{array}{l}\text { UPFC location in line connected between } \\
\text { buses }\end{array}$} \\
\hline & & 141 and 142 & 181 and 141 & 181 and 70 \\
\hline $\mathscr{L}_{\mathrm{L}}$ & - & 1.8679 & 2.1733 & 1.6192 \\
\hline$L_{\max }$ & 0.9750 & 0.8522 & 0.8509 & 0.8727 \\
\hline$V_{\min }$ & 0.8207 & 0.8532 & 0.8552 & 0.8550 \\
\hline $\begin{array}{l}\text { Power } \\
\text { loss (MW) }\end{array}$ & 235.91 & 228.99 & 224.60 & 225.37 \\
\hline MSV & 0.1120 & 0.1322 & 0.1401 & 0.1281 \\
\hline
\end{tabular}

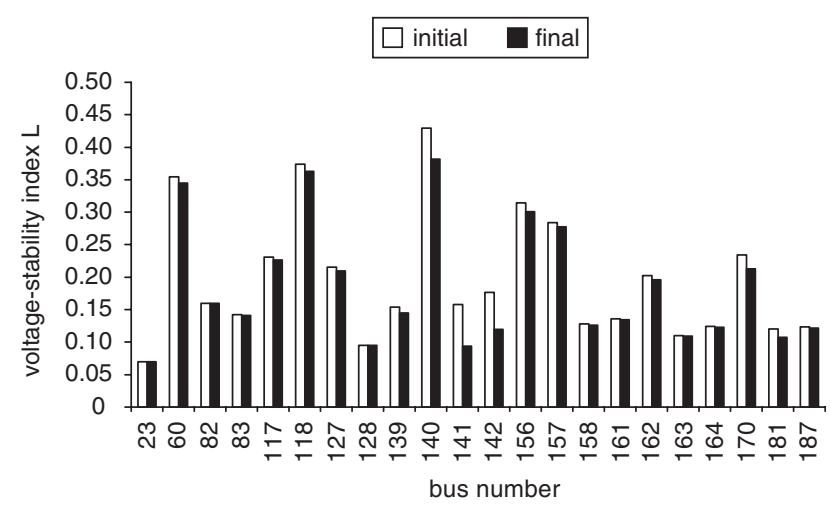

Fig. 13 Voltage-stability indexes

Rank-4 contingency

It can be seen from Table 10 that the UPFC location in line 181-141 has a high value for $\mathscr{L}_{\mathrm{L}}$, which indicates that the improvement in voltage-stability indexes is more than for the UPFC location in other lines. Also, the values of $L_{\max }$ and power loss are less for the UPFC location in line 181-141. Note that the MSV is higher, as shown in Table 10. Therefore the most suitable line for UPFC placement under the rank-4 contingency is 181-141. The initial and final (best location) bus-voltage-stability indexes of the selected $400 \mathrm{kV}$ buses in both cases are shown in Fig. 13.

\subsubsection{Rank-7 contingency (line outage 170-}

140): In this contingency, for a peak-load condition, the overall total real power loss is $233.57 \mathrm{MW}(2.84 \%)$. The minimum voltage is 0.8372 p.u. at bus 7 and the maximum voltage-stability index $L_{\max }$ is 0.9190 at bus 7. The selected transmission corridors for possible UPFC placements under
Table 11: Summary of results of UPFC placement under rank-7 contingency

\begin{tabular}{|c|c|c|c|c|}
\hline \multirow[t]{2}{*}{ Parameter } & \multirow[t]{2}{*}{ Initial } & \multicolumn{3}{|c|}{$\begin{array}{l}\text { UPFC location in line connected between } \\
\text { buses }\end{array}$} \\
\hline & & 141 and 142 & 181 and 141 & 181 and 170 \\
\hline $\mathscr{L}_{\mathrm{L}}$ & - & 1.7080 & 1.2298 & 2.0594 \\
\hline$L_{\max }$ & 0.9190 & 0.8924 & 0.8405 & 0.8404 \\
\hline$V_{\min }$ & 0.8372 & 0.8559 & 0.8562 & 0.8596 \\
\hline $\begin{array}{l}\text { Power } \\
\text { loss (MW) }\end{array}$ & 233.57 & 227.85 & 231.52 & 226.16 \\
\hline MSV & 0.1117 & 0.1311 & 0.1294 & 0.1378 \\
\hline
\end{tabular}

rank-7 contingency are the lines connected between buses 141 and 142, 181 and 141 and 181 and 70. The summary of results of UPFC placement under rank-7 contingency is given in Table 11.

From Table 11, it can be seen that the UPFC location in line 181-170 has a high value for $\mathscr{L}_{\mathrm{L}}$, which indicates that the improvement in voltage-stability indexes is more than for the UPFC location in other lines. Also, the values of $L_{\max }$ and power loss are less for the UPFC location in line 181-70. Note that the MSV is higher, as shown in Table 11. Therefore the most suitable line for UPFC placement is 181-170 under the rank-7 contingency. The initial and final (best location) bus-voltage-stability indexes of the selected $400 \mathrm{kV}$ buses in both cases are shown in Fig. 14.

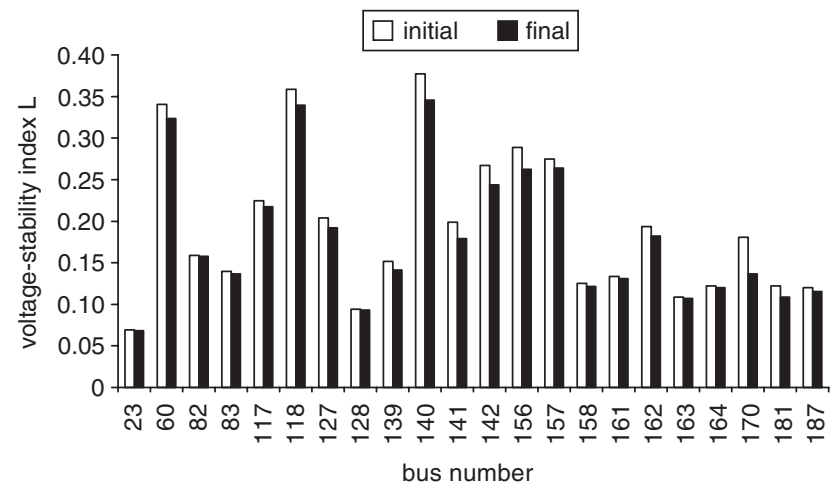

Fig. 14 Voltage-stability indexes Rank-7 contingency

\section{Conclusions}

The unified-power-flow controller (UPFC) improves system performance under normal and network-contingency conditions. Because UPFC is very expensive, it is important to ascertain the location for placement of the UPFC device most suitable for various network contingencies.

In this paper, in addition to real power loadings and bus voltages, the voltage-stability indexes at the load buses are also used as the postcontingent quantities to evaluate the network composite contingency ranking. The fuzzy contingency-ranking method effectively eliminates the masking effect of other methods of contingency ranking.

The selection of UPFC location under contingencies uses the voltage-stability $\mathrm{L}$ index of load buses and minimum singular value as the basis. The proposed approach for selection of suitable locations for UPFC has been tested under simulated conditions on a few power systems and the results for a 205-node real-life equivalent regional-power- 
grid system of three interconnected utility systems are presented for illustration purposes.

\section{References}

1 Ewald, E., and Angland, D.W.: 'Regional integration of electric power systems', IEEE Spectrum, April 1964, pp. 96-101

2 Galiana, F.D.: 'Bound estimates of the severity of line outages', IEEE Trans., 1984, PAS-103, pp. 2612-2624

3 Sidhu, T.S., and Cui, L.: 'Contingency screening for steady state security analysis by using FFT and ANNs', IEEE Trans., 2000, PS-15, pp. $421-426$

4 Ejebe, G.C., and Wollenberg, B.F.: 'Automatic contingency selection', IEEE Trans., 1974, PAS-93, pp. 859-869

5 Halpin, T.F., Fischi, R., and Fink, R.: 'Analysis of automatic contingency selection algorithms', IEEE Trans., 1984, PAS-103, pp. $938-945$

6 Yuan, Y.H. and Kuo, $\mathrm{H}$. 'Fuzzy set based contingency ranking', IEEE Trans., 1992, PS-7, (3), pp. 1189-1196

7 Bansilal, Thukaram, D., and Parthasarathy, K.: 'Optimal reactive power dispatch algorithm for voltage stability improvement', Elect. Pwr. Energy Syst., 1996, 18, (7), pp. 461-468
8 Udupa, A.N., Thukaram, D., and Parthasarathy, K.: 'An expert fuzzy control approach to voltage stability enhancement', Elect. Pwr. Energy Syst., 1999, 21, pp. 279-287

9 IEEE Power Engineering Society/CIGRÉ: FACTS overview, IEEE Service center, Piscataway, NJ, USA 1995. Special; Issue 95TP108

10 IEEE Power Engineering Society/CIGRÉ: FACTS applications, IEEE Service center, Piscataway, NJ, USA 1996. Special; Issue 96TP116-0

11 Galiana, G.D. et al.: 'Assessment and control of the impact of FACTS devices on power system performance', IEEE Trans., 1996, PS-11, (4), pp. 1931-1936

12 Lof, P.A. et al.: 'Fast calculation of a voltage stability index', IEEE Trans., 1992, PS-27, (1), pp. 54-64

13 Kessel, P., and Glavitsch, H.: 'Estimating the voltage stability and loadability of power systems', IEEE Trans., 1986, PD-1, (3), pp. $1586-1599$

14 Fuerte-Eaquivel, C.R., and Acha, E.: 'Unified power flow cotroller: a critical comparison of Newton-Raphson UPFC algorithms in power flow studies', IEE Proc.- Gern. Trans. Distrib., 1997, 144, (5), pp. $437-444$

15 Watts D.: 'Security \& vulnerability in electric power system'. 35th North American Power Symposium (NAPS 2003), University of Missouri-Rolla, Oct. 2003, pp. 559-566 